\title{
Correction to: Evaluation of drug-drug interactions of pemigatinib in healthy participants
}

\author{
Tao Ji ${ }^{1}$ (1) $\cdot$ Kevin Rockich ${ }^{1} \cdot$ Noam Epstein ${ }^{1,2} \cdot$ Heather Overholt ${ }^{1} \cdot$ Phillip Wang $^{1} \cdot$ Xuejun Chen $^{1} \cdot$ Naresh Punwani $^{1}$. \\ Swamy Yeleswaram ${ }^{1}$
}

Published online: 26 August 2021

๑) Springer-Verlag GmbH Germany, part of Springer Nature 2021

\section{Correction to: European Journal of Clinical Pharmacology https://doi.org/10.1007/s00228-021-03184-z}

An error occurred in the abstract of the manuscript published online ahead of print. The order of "AUC" and " $\mathrm{C}_{\max }$ " was erroneously reversed in the following sentence in the abstract Results section: "There was a 35\% and $8 \%$ decrease in pemigatinib AUC and $\mathrm{C}_{\max }$, respectively, with esomeprazole...." This sentence should read "There was a $35 \%$ and $8 \%$ decrease in pemigatinib $\mathrm{C}_{\max }$ and AUC, respectively, with esomeprazole...." The authors apologize for this error and any inconvenience caused.

Publisher's Note Springer Nature remains neutral with regard to jurisdictional claims in published maps and institutional affiliations.

The original article can be found online at https://doi.org/10.1007/ s00228-021-03184-z.

Tao Ji

tji@incyte.com

1 Incyte Research Institute, 1801 Augustine Cut-off,

Wilmington, DE 19803, USA

2 GlaxoSmithKline, Collegeville, Philadelphia, PA, USA 